\title{
Quantifying patterns of fish herbivory on Palmyra Atoll (USA), an uninhabited predator-dominated central Pacific coral reef
}

\author{
Scott L. Hamilton ${ }^{1}$, Jennifer E. Smith ${ }^{2}$, Nichole N. Price ${ }^{2}$, Stuart A. Sandin ${ }^{2, *}$ \\ ${ }^{1}$ Moss Landing Marine Laboratories, 8272 Moss Landing Rd., Moss Landing, California 95039, USA \\ ${ }^{2}$ Center for Marine Biology and Conservation, Scripps Institution of Oceanography, 9500 Gilman Drive, La Jolla, \\ California 92093, USA
}

\begin{abstract}
On many coral reefs, herbivorous fish play an essential role in regulating algal growth and influencing the outcome of coral-algal competition. Working on a remote predator-dominated coral reef on Palmyra Atoll, USA, we used behavioral foraging observations to quantify the roles of common parrotfish and surgeonfish in the roving herbivore guild. We recorded species-specific bite rates on different benthic organisms, quantified the relative abundance of those benthic organisms, and estimated benthos-specific grazing intensities as a function of bite rates, fish abundance, and percent cover. These grazing metrics were compared between the exposed fore reef ( $10 \mathrm{~m}$ depth) and protected reef terrace ( $\sim \mathrm{m}$ depth) habitats. We observed large differences in feeding rates and substrate selectivity among fish species. Most species fed predominately on algal turfs; however, some species foraged broadly among fleshy macroalgal taxa, while others specialized on calcified green algae of the genus Halimeda. The highest bite rates were recorded from species targeting algal turfs, while the highest rates of defecation were recorded from species targeting Halimeda. Per capita bite rates of all species were higher in the fore reef habitat (mean $45 \%$ more bites $\mathrm{min}^{-1}$ ); however, overall grazing intensities on turf algae (bites $\mathrm{cm}^{-2} \mathrm{~d}^{-1}$ ) were 5 times higher on the reef terrace than on the fore reef. Despite habitat-specific differences in the herbivore assemblages, the estimated distribution of total bites showed consistency among habitats, with strong guild-level positive foraging selectivity for algal turf. Comparisons of bite and defecation rate data for these herbivores across the Indo-Pacific highlight phylogenetic constraints on grazing activities. Overall, this study illustrates the importance of herbivore functional redundancy, variability in species-specific grazing, and provides a framework for assessing guildwide grazing impacts on coral reefs.
\end{abstract}

KEY WORDS: Behavioral foraging observations $\cdot$ Bite rates $\cdot$ Defecation rates · Grazing impacts · Macroalgae $\cdot$ Parrotfish $\cdot$ Surgeonfish

\section{INTRODUCTION}

Top-down consumer effects on prey species are well known to cascade through food webs with effects on community structure and ecosystem function (Strong 1992, Terborgh \& Estes 2010, Estes et al. 2011). On coral reefs, herbivorous fish are essential players in controlling algal biomass, thus helping to favor corals by preventing the establishment and growth of algae that compete for space and inhibit coral recruitment (Lewis 1986, Choat 1991, Hughes et al. 2007, Burkepile \& Hay 2008). In some locations, herbivorous fish are the primary consumers of algal production (Carpenter 1986, van Rooij et al. 1998). However, the loss of herbivores from coral reefs over the past several decades is considered one of the pri- 
mary local factors responsible for the current degradation of these iconic ecosystems and has raised alarms for management action (Bellwood et al. 2004, Mumby \& Steneck 2008). In locations where herbivores have recovered in biomass, such as inside notake marine reserves, their foraging activities have been shown to reduce algal cover and promote coral growth and recruitment (Mumby et al. 2006, Hughes et al. 2007, Mumby \& Harborne 2010). Therefore, herbivory is often acknowledged to be a key ecological process structuring benthic communities and influencing resilience of coral reefs.

Determining the functional roles of herbivorous fish and quantifying their impacts on coral reefs is essential for ecosystem-based management. Previous studies have measured the grazing and bioerosion rates for a variety of roving herbivorous parrotfish and surgeonfish in the Indo-Pacific (Bellwood \& Choat 1990, Choat \& Clements 1993, Bellwood 1995, Polunin et al. 1995, Fox \& Bellwood 2007, Alwany et al. 2009, Ong \& Holland 2010, Goatley \& Bellwood 2010). These studies have revealed that all herbivores are not equal in their foraging patterns and food selectivity due to differences in dentition, digestive anatomy, foraging habitats, and body size, among other factors. Therefore, it is important to consider individually the grazing activities of species in order to build an accurate depiction of the aggregate effects of entire herbivore guilds on the reef benthos. Recent studies have highlighted the critical and synergistic importance of herbivore diversity in controlling the growth of different seaweed species (Bellwood et al. 2006, Burkepile \& Hay 2008, 2010). Currently, efforts are being made to better understand the importance of functional redundancy and herbivore diversity for enhancing coral reef resilience in the face of climate change and other stressors (Elmqvist et al. 2003, Nystrom 2006, Cheal et al. 2010). However, few of these studies have been conducted in what may be considered 'pristine' systems, with intact food webs and minimal harvesting of top predators and herbivorous fish.

While grazing rates have been shown to differ between species in many locations, grazing rates may also differ within a species across different reef habitats as a function of algal productivity, resource availability, or benthic community composition (Fox $\&$ Bellwood 2007). These factors often differ along depth gradients and between reef zones and are likely to influence patterns of herbivory, herbivore community composition, and the ability of herbivores to control the growth of algal resources. Previous studies have quantified the foraging activities and bioerosion rates of the dominant herbivorous fish (e.g. Bellwood 1995, Fox \& Bellwood 2007); however, few have attempted to quantify grazing and excretion activities of all parrotfish and surgeonfish comprising the roving herbivorous assemblage in a single reef or across multiple reef zones, especially for unfished herbivore assemblages (but see Bellwood \& Choat 1990 for a full analysis of parrotfish foraging on the Great Barrier Reef).

Our goals were to quantify the abundance, grazing rates, and substrate-specific grazing intensities of all common species of parrotfish and surgeonfish on Palmyra Atoll, USA, and compare differences in functional roles and patterns of herbivory between the exposed fore reef and protected reef terrace habitats. We asked the following questions: (1) How variable are bite rates and bite composition across herbivore species and reef habitats? (2) Is there evidence for functional redundancy or functional flexibility among species? We hypothesized that foraging behaviors and reef-wide grazing pressure would de driven by habitat-specific fish assemblage structure and benthic composition. To address these questions we first recorded the abundance and biomass of herbivorous fishes and the percent cover of benthic organisms at multiple sites in 2 habitats. Next, we assessed the relative grazing activities of parrotfish and surgeonfish on different benthic substrate types through direct foraging observations and calculated how standardized grazing activities differ among and within species between different habitats. Finally, we attempted to place our herbivory data in context with results from other studies conducted on the same species throughout the Indo-Pacific. The current and historical lack of fishing on Palmyra provides a unique baseline to assess spatial variation in herbivore foraging behavior in the absence of confounding influences of human exploitation on herbivores or their predators.

\section{MATERIALS AND METHODS}

\section{Study location}

All research was conducted on Palmyra Atoll $\left(5^{\circ} 53^{\prime} \mathrm{N}, 162^{\circ} 07^{\prime} \mathrm{W}\right)$, located in the remote Northern Line Islands chain, $1600 \mathrm{~km}$ south-southwest of the Hawaiian Archipelago (Fig. 1). Palmyra represents a unique ecosystem because of its isolation and lack of direct local human impacts; It has been a US National Wildlife Refuge since 2001 and part of the Pacific Remote Islands Marine National Monument since 

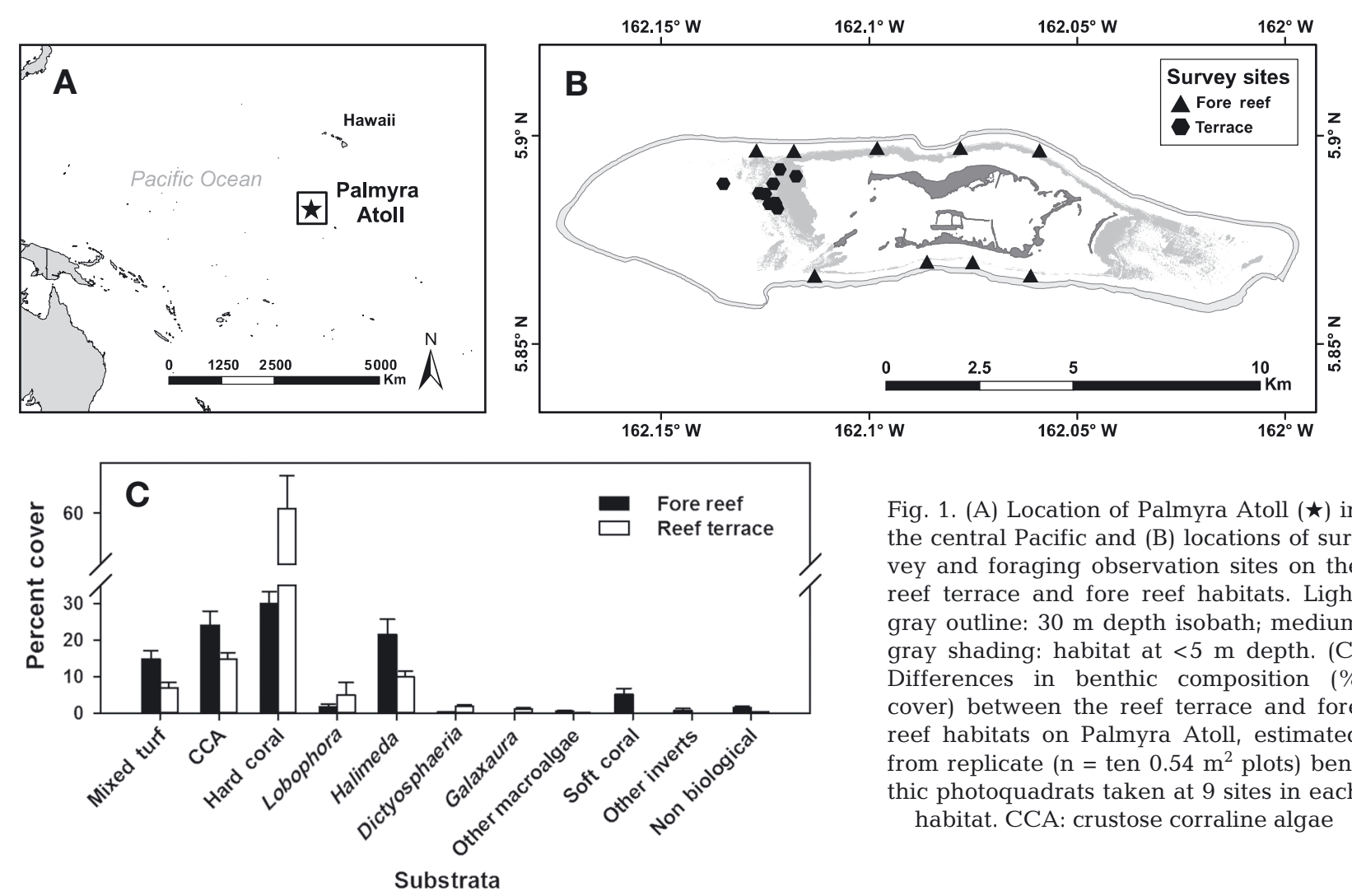

Fig. 1. (A) Location of Palmyra Atoll ( $\star$ ) in the central Pacific and (B) locations of survey and foraging observation sites on the reef terrace and fore reef habitats. Light gray outline: $30 \mathrm{~m}$ depth isobath; medium gray shading: habitat at $<5 \mathrm{~m}$ depth. (C) Differences in benthic composition (\% cover) between the reef terrace and fore reef habitats on Palmyra Atoll, estimated from replicate $\left(\mathrm{n}=\right.$ ten $0.54 \mathrm{~m}^{2}$ plots) benthic photoquadrats taken at 9 sites in each habitat. CCA: crustose corraline algae

2009. Fishing and non-scientific extraction are prohibited and were limited for decades prior, and the atoll houses only a small research station. Palmyra is a predator-dominated coral reef system with globally high values of apex predator biomass (Sandin et al. 2008). The coral reefs of Palmyra are considered to be relatively healthy with reef building corals and crustose coralline algae (CCA) making up $>50 \%$ of the benthic cover on the fore reef slope $(10 \mathrm{~m})$ and shallow reef terrace (5 $\mathrm{m}$ depth) (54 and $78 \%$ cover, respectively; Fig. 1C) (Williams et al. 2013). Calcified green algae in the genus Halimeda are by far the most common macroalgae on Palmyra's reefs and account for on average 22 and $10 \%$ of total benthic cover on the fore reef and reef terrace habitats, respectively (Fig. 1). There is an extremely low density of herbivorous echinoids on Palmyra, so fish are the primary large-bodied grazers in this system (Sandin et al. 2008).

\section{Fish and benthic community surveys}

Surveys of fish and benthic assemblages were conducted using SCUBA-assisted coral reef assessment techniques from August to September 2008, at 9 shallow reef terrace (3-6 m depth) and 9 fore reef
(10-12 m depth) sites (Fig. 1). The shallow reef terrace sites were located on the western end of Palmyra and separated from one another by over $500 \mathrm{~m}$, while the fore reef sites were separated by $1 \mathrm{~km}$ and split among the northern and southern exposed shores of the atoll.

At each site, a team of paired divers enumerated all fishes within fixed-length $(25 \mathrm{~m})$ strip transects whose widths differed depending on fish body size: $8 \mathrm{~m}$ wide for fishes $\geq 20 \mathrm{~cm}$ total length (TL), and $4 \mathrm{~m}$ wide for fishes $<20 \mathrm{~cm}$ TL. Each site had 3 transects, $\sim 10 \mathrm{~m}$ apart. Thus, at each site, fish densities were estimated within a $600 \mathrm{~m}^{2}(3 \times 25 \times 8 \mathrm{~m})$ area for large-bodied fishes, and $300 \mathrm{~m}^{2}(3 \times 25 \times 4 \mathrm{~m})$ area for small fishes. Transect bearings were determined haphazardly along isobaths. Each diver was responsible for one-half of the area surveyed. On an initial 'swim-out' as the transect line was laid, large-bodied fishes were tallied within 2 adjacent $4 \mathrm{~m}$ wide swaths. Small-bodied fishes were tallied within 2 adjacent $2 \mathrm{~m}$ wide swaths centered on the transect line on the return swim. Fishes were recorded by species (or lowest recognizable taxon) and size class (binned into $5 \mathrm{~cm}$ TL classes). Transects allowed us to estimate species- and size-specific numerical densities. Various published (Kulbicki et al. 2005), unpublished (J. D. Parrish, US Geological Survey, Hawaii 
Cooperative Fishery Research Unit), and web-based (Froese \& Pauly 2007) sources provided lengthweight regression parameters necessary for converting abundance to biomass. We report here data from fish $>5 \mathrm{~cm}$ TL, as the effects of juveniles and smaller fish within the herbivore guild are likely limited.

Quantitative assessments of the benthos were made using modifications to the photoquadrat method (Preskitt et al. 2004). At each site, two $25 \mathrm{~m}$ transects were placed on the benthos parallel to shore, and 10 points were randomly selected and surveyed per transect. At each point a photograph was taken using a Canon G9 digital camera that was connected to a quadpod (1 $\mathrm{m}$ high) and a frame $\left(0.9 \times 0.7 \mathrm{~m}\right.$ or $\left.0.63 \mathrm{~m}^{2}\right)$. During surveys, notes were made for each quadrat and collections were made for organisms that were unidentifiable in the field. Upon return to shore all photographs were edited using Adobe Photoshop CS3. Image analysis was completed using the program Photogrid 1.0. For each photograph, 100 points were generated in a stratified random fashion, and the organism under each point was identified. All organisms were identified to the finest level of resolution possible (genus level for hard and soft corals, functional group for algal turfs and CCA, and genus or species level for macroalgae and macroinvertebrates when possible). Data were collapsed and are presented here as percent cover of the following functional groups: hard coral, soft coral, CCA, turf algae, fleshy and calcified macroalgae, other invertebrates and non-biological substrata (e.g. sand).

\section{Bite rate observations}

To quantify the impact of roving herbivorous and nominally herbivorous (i.e. detritivorous) fishes on Palmyra's coral reefs, we conducted focal behavioral observations on the most common species of parrotfish (subfamily Scarinae) and surgeonfish (family Acanthuridae) present in the shallow reef terrace and fore reef sites visited for benthic and fish community surveys. The species observed represented 94 and $84 \%$ of the combined abundance of surgeonfish and parrotfish on the reef terrace and fore reef, respectively. Some species of fish only occurred in one of the reef habitats on Palmyra, while other species inhabited both the reef terrace and fore reef. Divers followed focal fish for 3 to 6 min $(4.0 \pm 0.03$ $\mathrm{SE}$ ) per observation at a distance of 2 to $3 \mathrm{~m}$ behind the fish (similar to methods reported in Bellwood 1995, Fox \& Bellwood 2007), to avoid disturbing its behavior, and recorded the number of bites taken on a several different benthic substrate categories, including mixed turf algae (epilithic algal matrix), CCA, Halimeda spp. (primarily H. opuntia), Lobophora variegata, Galaxaura rugosa, Dictyosphaeria spp. (both $D$. cavernosa and D. verslusii), sand, and hard coral. For the duration of the observation the number of defecations was recorded. We recorded the time of day, size (TL to nearest $\mathrm{cm}$ ), and sexual class (for sex-changing parrotfish) of each individual at the start of the observation period. Observations were repeated multiple times at different phases of the diel cycle at all sites between 10:00 and 16:00 h each day (due to logistical constraints at a remote field station).

For each species we calculated the mean number of bites $\min ^{-1}$ and the proportion of bites on the 7 most common substrate types. In order to estimate the total foraging impact of herbivores on the benthos (i.e. the 'rain of bites' across the landscape), bite rates for each species were multiplied by speciesspecific density and the total time spent foraging per day to calculate the number of bites per unit area per day in each the reef terrace and fore reef habitat. We assumed a $10 \mathrm{~h}$ day available for foraging because although Palmyra receives $12 \mathrm{~h}$ of daylight near the equator, parrotfish do not initiate foraging immediately at sunrise and often forage less in the hour after sunrise and before sunset (Bellwood 1995). Finally, we calculated a substrate-specific grazing intensity, estimated as the number of bites taken per unit area of each substrate type per day. For each species $\times$ substrate combination, substrate-specific grazing intensity was calculated as the density of fish times the species-specific foraging rate on the particular substrate, divided by the percent cover of the substrate. Values were calculated independently for the reef terrace and fore reef habitats and were scaled to units of bites $\mathrm{cm}^{-2}$ (of substrate) $\mathrm{d}^{-1}$. We used mean bite rates of the closest congener for a few of the rarer species that were not followed in each habitat. By summing values across fish species, we report values of substrate-specific grazing intensity for all herbivorous fish combined, for all herbivores excluding Ctenochaetus spp. (which are primarily detritivores that ingest detritus from benthic surfaces with soft comb-like teeth; but see Marshell \& Mumby 2012), and separately for parrotfish and surgeonfish (including Ctenochaetus spp.). We also compare differences in grazing intensity on each substrate between the reef terrace and fore reef and calculate changes in bite rates between habitats for those species that cooccur on the reef terrace and fore reef. 
Finally, we asked whether defecation frequency was related to the diet of parrotfish and surgeonfish by examining relationships between defecation frequency and the proportion of bites taken on various substrates.

\section{Statistical analysis}

Statistical analyses were completed using R (R Development Core Team 2010) unless otherwise stated. Tests were designed with specific reference to the nature and distributions of the response data. Data describing the benthic composition and foraging selectivity of fishes are in units of percentages. Importantly, when considering percentage data, there is clear non-independence of percentage values within one sample. For example, if a sample is composed of $90 \%$ of one benthic type, the other benthic types are constrained to be relatively rare and compose only a total of $10 \%$. If there are many different groups composing an individual sample (again, with percentages of groups summing to $100 \%$ ), the responses of each group can begin to appear fairly independent. In these cases, authors will often employ statistics that depend upon the assumption of independence of response variables (e.g. ANOVA). When there are fewer groups or when the assumption of independence cannot be approximated, alternative statistical approaches must be used. We employed bootstrapping to test whether observed distributions of percentage profiles (i.e. relative amounts of benthic types or relative preferences of herbivores) deviated from a null expectation. Importantly, our tailored resampling approaches answer questions about the estimated location of groupspecific mean percentage profiles (i.e. centroids of percentage profiles in multinomial space). This is distinct from multidimensional statistical tools such as ANOSIM that answer questions about patterns of similarity within and between groups of multidimensional data, without directly considering the location of the multidimensional mean.

In order to test whether the proportion of benthic types differed between habitats, we used a resampling approach (Barott et al. 2012). Briefly, sitespecific mean benthic configurations (vectors of percent covers across 11 benthic types, each vector summing to 100) were plotted in 11-dimensional space. The centroids of the 9 site estimates for each habitat (i.e. forereef and reef terrace) were calculated and the Euclidean distance between centroids was recorded. A null distribution of inter-centroid distances was created (with 10000 re-sampled replicates, assuming that group membership contains no information about the variability in the data). If the true distance between the centroids was in either of the most extreme 0.025 percentiles, then the true benthic configurations were considered significantly different from one another at the $\alpha=0.05$ significance level. In practice, this resampling approach is comparable to the logic underlying the 1-dimensional statistical analog of the $t$-test (Barott et al. 2012).

To assess herbivore preferences for particular substrata (live coral, CCA, macroalgae, Halimeda spp., or mixed turf algae $<2 \mathrm{~cm}$ in height), we used Manly's $\alpha$ selectivity indices (Chesson 1983) calculated as:

$$
\hat{\alpha}_{i}=\frac{r_{i} / n_{i}}{\sum_{j=1}^{m} r_{j} / n_{j}}, i=1, \ldots, m
$$

where $r_{i}$ is the total bite rate (fish density $\mathrm{m}^{-2} \times$ bites $\mathrm{h}^{-1}$ ) on substrate $i$ of $m=5$ substrate types. The bite rate is divided by the proportion $n$ of any substratum $i$ available for consumption. Substrate-specific $\alpha$ 's were calculated for each species or group of fishes (parrotfishes or surgeonfishes) in each habitat (reef terrace or fore reef). The null index ( $\alpha=0.2$ for 5 substrate categories) represents 'no preference' because relative grazing intensity (or proportion of bites) is evenly distributed across each substrate, given its relative abundance in each habitat. Values of $\alpha$ significantly below the null represent 'avoided' substrates; values significantly above $\alpha=0.2$ represent substrates grazed more often than expected based on availability and random grazing behavior.

To test for significance in the differences of selectivity profiles from null, we employed a resampling approach analogous to the comparison of multinomial percent cover estimates across habitats, as described above. Note that selectivity profiles as defined here are multinomial representations of the relative bias toward or away from potential food resources. Of interest statistically is to know whether or not our confidence in the location of this multinomial selectivity profile (in $n$-dimensional space, where $n$ is the number of potential food resources) contains the null expectation of no bias for any food resource ( $\alpha=0.2$ for each of 5 food resources). We explored this question for the selectivity profiles for all herbivorous fishes by resampling our raw data to generate multinomial confidence intervals around the estimated selectivity profile. Statistical error in these habitat-specific estimates is introduced through both the estimation of species-specific density and of species-specific bite rates. Bootstrapped confidence 
intervals for the multinomial selectivity were generated in a 5-step process for each habitat: (1) means \pm SE were estimated for both the density and bite rate of each species; (2) values from these distributions were drawn randomly for each species and multiplied (thus describing an estimated species-specific bite rate weighted by species density); (3) the total bite rate was multiplied by the species-specific vector of bite distributions (i.e. the fraction of bites made on each benthic type); (4) these bite rates were summed across species for each benthic type to generate a resampled estimate of the 'rain of bites', and (5) the selectivity profile of this resampled estimate of bites was calculated, recorded, and the process was repeated 10000 times. The distribution of these resampled selectivity profiles was compared against our multinomial null (i.e. $\alpha=0.2$ for each benthic type) by estimating the distribution of distances of each realization from the null, when the distance is projected onto the axis linking the null and the centroid of the resampled selectivity profiles. If fewer than $2.5 \%$ of the bootstrapped confidence interval spanned the null, the estimated selectivity profile was considered significantly different from the null.

Herbivore biomass and density were compared across habitats using a 2-way ANOVA with habitat and herbivore group (parrotfish and surgeonfish) both treated as fixed effects. Total bite rates were compared across habitats using a 2-sample $t$-test. We used principal components analysis (PCA) to assess similarities and differences within and among species in foraging behavior using the substrate-specific bite rate data across species and habitats. Estimates of bite rates and defecation rates were related to hypothesized drivers, such as the proportion of bites taken on different substrate types, using a simple linear regression.

\section{RESULTS}

\section{Fish and benthic surveys in two reef habitats}

The reef terrace and fore reef of Palmyra Atoll differed significantly in benthic community composition ( $p<0.001$; Fig. 1). The shallow reef terrace is dominated by hard corals (60.2\% cover), with common taxa being species of encrusting and plating Montipora $(31.9 \%)$, branching and plating Acropora (20.5\%) and Pocillopora (2.9\%). Other top substrate types on the reef terrace include CCA (14.6\%), Halimeda spp. (9.9\%), turf algae (6.9\%), and Lobophora variegata $(5 \%)$. The fore reef is characterized by lower coral cover $(29.2 \%)$ than the reef terrace, and the dominant coral species here are small Pocillopora $(8.4 \%)$, Porites $(5.7 \%)$, Montipora $(3.1 \%)$ and Favia $(3.1 \%)$. Other top substrate types on the fore reef include CCA (25.6\%), Halimeda spp. (20.5\%), turf algae $(14.7 \%)$, and other substrata $(8.6 \%)$, such as soft corals and anemones. The main differences between the habitats are higher coral cover on the reef terrace and higher CCA, Halimeda, and turf algae cover on the fore reef. The less common taxa also differ between the habitats.

The density of herbivorous fishes ( $>5 \mathrm{~cm}$ TL) was 3.1 and 2.3 times higher at reef terrace sites than fore reef sites (Fig. 2A). Herbivorous fish densities differed between habitats and between families (surgeonfish were more abundant), but there was no significant interaction term suggesting the pattern was consistent (2-way ANOVA, Habitat: $F_{1,32}=32.8$, p < 0.0001; Family: $F_{1,32}=32.2, \mathrm{p}<0.0001$; Habitat $x$ Family: $\left.F_{1,32}=3.1, \mathrm{p}=0.09\right)$. The biomass $\left(\mathrm{g} \mathrm{m}^{-2}\right)$ of herbivorous parrotfish and surgeonfish were both $\sim 1.5$ times higher in the reef terrace habitat than the fore reef (Fig. 2B), but there were no differences in biomass between herbivore families and there was
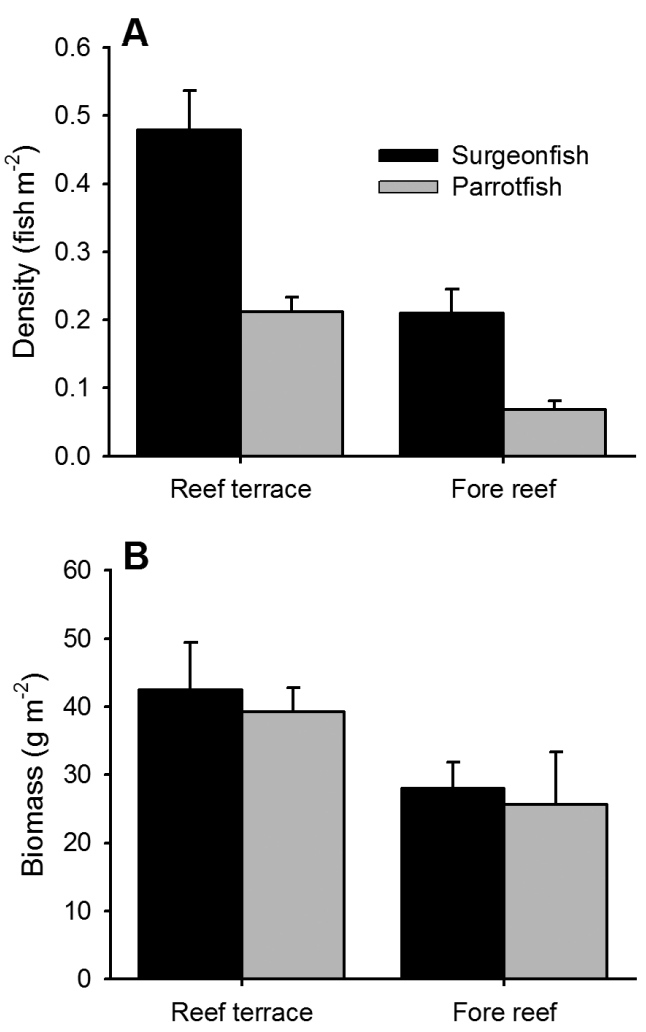

Fig. 2. Chlorurus spp., Scarus spp., Acanthurus spp., Ctenochaetus spp. (A) Biomass and (B) density of surgeonfish (black) and parrotfish (gray) in 2 different reef habitats on Palmyra Atoll. Data: mean $\pm 1 \mathrm{SE}$ 
no significant interaction term (Habitat: $F_{1,32}=5.8$, $\mathrm{p}=0.022$; Family: $F_{1,32}=0.2, \mathrm{p}=0.64$; Habitat $\times$ Family: $\left.F_{1,32}=0.0045, \mathrm{p}=0.95\right)$. The differences in herbivorous fish abundance between the 2 habitats were magnified when considering fish density (fish $\mathrm{m}^{-2}$ ) as opposed to fish biomass because more juveniles (>5 cm TL) were observed in the reef terrace while the fore reef was mainly inhabited by larger adults. The most common species of herbivorous fish in terms of density and biomass on the reef terrace were the surgeonfish Ctenochaetus striatus, Acanthurus nigricans, and A. triostegus, and the parrotfish Chlorurus sordidus, C. microrhinos, Scarus frenatus, and $S$. oviceps (Fig. 3 and see Fig. S1 in the Supplement at www.int-res.com/articles/suppl/m501p141.pdf). On the fore reef the most common species of surgeonfish were Ctenochaetus cyanocheilus, C. marginatus, and A. nigricans, while the most abundant parrotfish were Chlorurus sordidus, S. frenatus, and S. rubroviolaceous (Figs. 3 \& S1).

\section{A. Reef terrace}

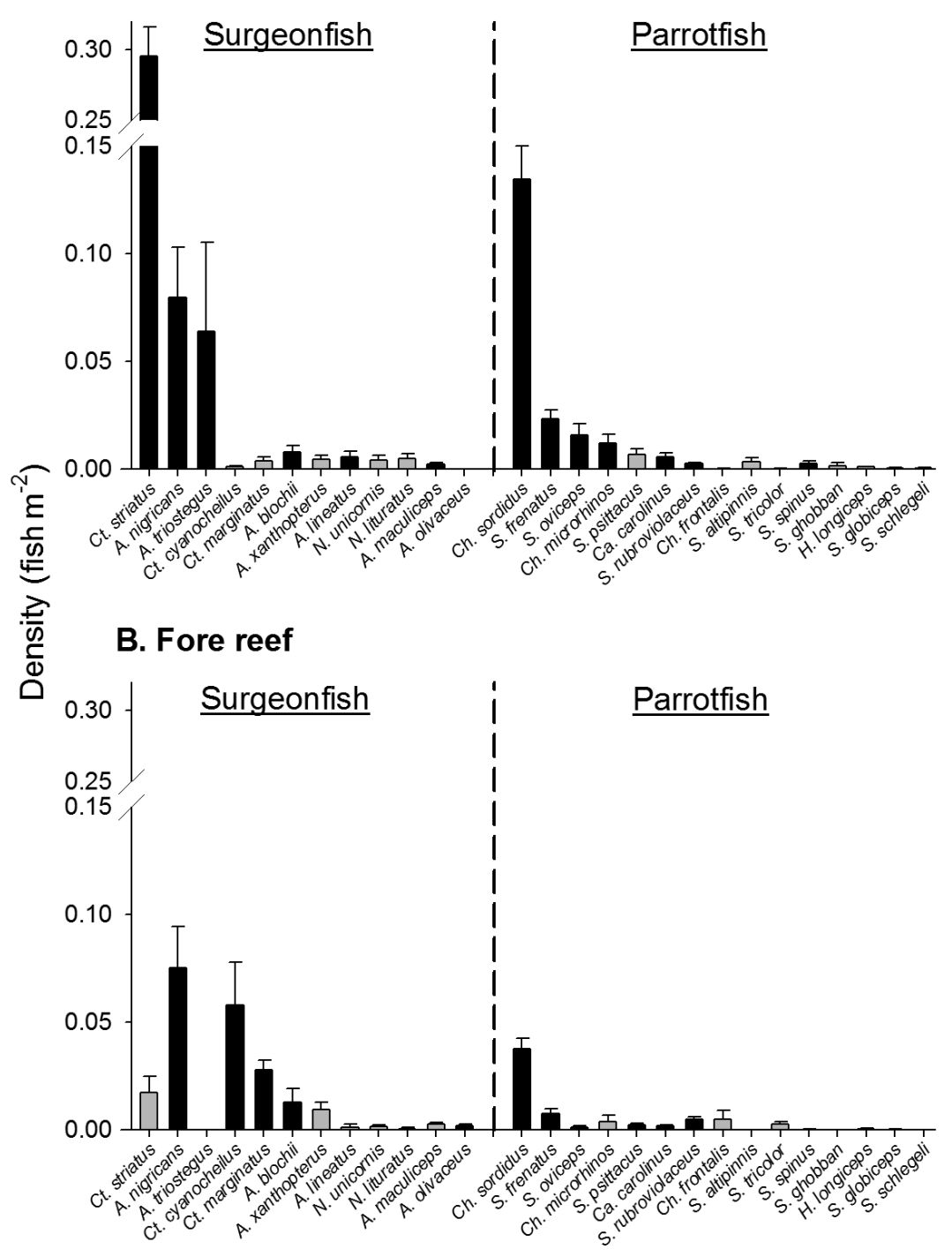

Fig. 3. Chlorurus spp., Acanthurus spp., Naso unicornis, N. lituratus, Ctenochaetus spp., Scarus spp., Hipposcarus longiceps, Calotomus carolinus. Densities (fish $\mathrm{m}^{-2}$ ) of all herbivorous fish species on (A) the reef terrace and (B) the fore reef of Palmyra Atoll. See Fig. S1 in the Supplement for species-specific biomass patterns in each habitat. Error bars: \pm 1 SE. Species are arranged from most abundant to least abundant for surgeonfish and parrotfish based on their global mean abundance at Palmyra. Black bars: focal species selected for foraging behavior observations in a particular habitat; gray bars: species that were not followed

\section{Behavioral observations and grazing intensity}

Through our behavioral observations, we recorded bite rate information on 25 species (12 parrotfish and 13 surgeonfish), followed a total of 489 individuals (305 on the reef terrace and 184 on the fore reef), and spent a total of $1884 \mathrm{~min}$ (1196 min on the reef terrace and $688 \mathrm{~min}$ on the fore reef) observing fish feeding on the reef at Palmyra Atoll. We limited this analysis to only the most common species observed, giving a total of 471 individuals observed from 21 species.

We observed distinct species-specific differences in total bite rates and the distribution of those bites among benthic substrates (Fig. 4; see Table S1 in the Supplement). The highest bite rates were observed for species of surgeonfish and parrotfish that focus their foraging efforts on turf algae. We recorded the highest bite rate for Scarus spinus averaging $>40$ bites $\mathrm{min}^{-1}$. Species that were excavators (e.g. Chlorurus microrhinos) tended to have lower bite rates than species that were scrapers (e.g. C. sordidus, S. frenatus), and species that favoured Halimeda tended to have the lowest bite rates. Some species of parrotfish and surgeonfish were generalists (e.g. Acanthurus blochii, A. olivaceus, Ctenochaetus spp., Chlorurus sordidus, S. rubroviolaceus), while most preferred either turf algae or Halimeda. Overall, foraging habits appeared to be more diverse, even for cooccurring species, on the reef terrace than the fore reef, potentially due to the increased availability of different macroalgal taxa in that habitat (Fig. 4, Table S1). 


\section{A. Reef terrace}

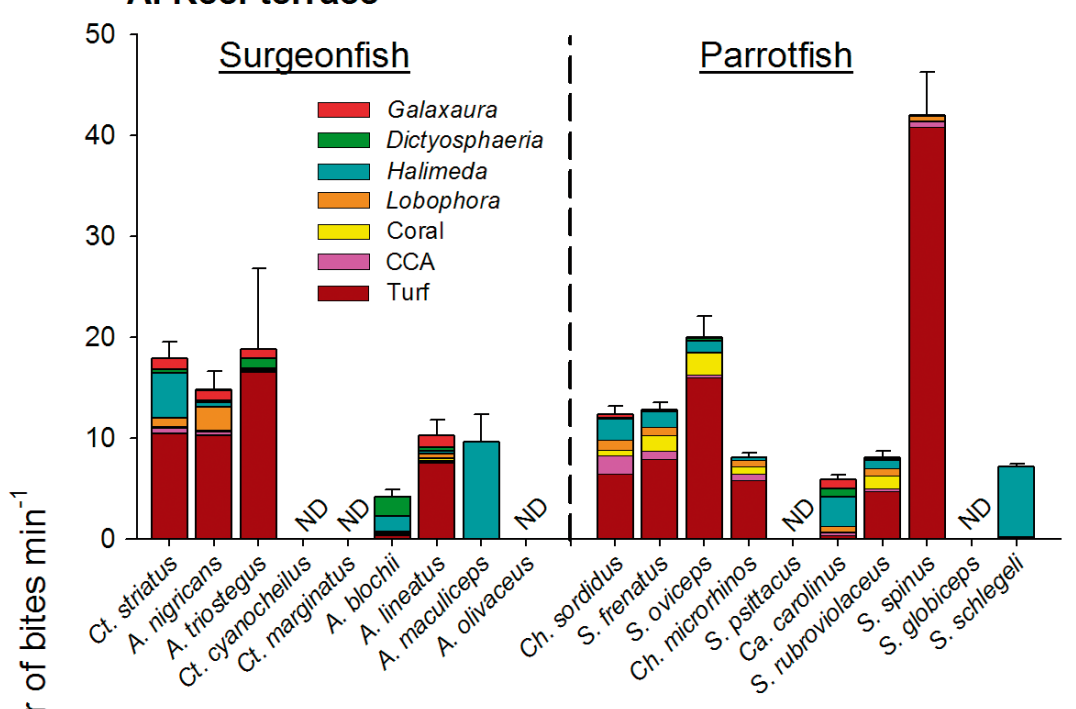

B. Fore reef

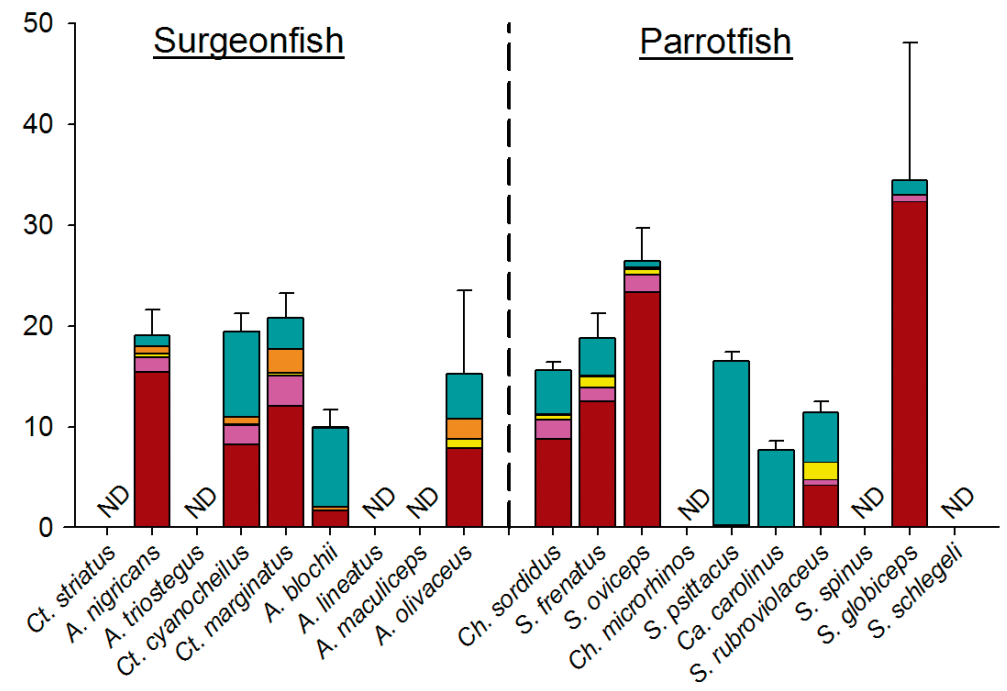

Fig. 4. Chlorurus spp., Scarus spp., Acanthurus spp., Ctenochaetus spp., Calotomus carolinus. Bite rates $\left(\mathrm{min}^{-1}\right)$ of focal herbivorous fish species on various substrate types on (A) the reef terrace and (B) fore reef of Palmyra Atoll. Data: average bite rates per individual per species $( \pm 1 \mathrm{SE})$. ND: no data

We compared bite rates for herbivorous parrotfish on Palmyra with values reported in the literature for other locations throughout the Indo-Pacific (Table 1). Species-specific feeding rates (primarily on turf algae) were remarkably similar within species but showed similar levels of variation between species, suggesting that foraging behavior is phylogenetically conserved across the Indo-Pacific.

PCA using bite rate and bite composition data for each individual indicated that among-species variability in foraging behavior was greater than withinspecies variability (Fig. 5). Some species exhibited high within-species diet variability (i.e. large error bars) indicative of occupying a broad dietary niche (e.g. Acanthurus blochiii, A. triostegus, Scarus globiceps), while most species appeared to have low diet variability (e.g. Chlorurus sordidus, C. microhinos, S. psittacus, S. frenatus), indicating a relatively narrow dietary niche. Species fell into groups based on similarities in diet composition, such that Halimeda specialists grouped differently from macroalgal browsers, and turf scraper/excavators. Habitat- and speciesspecific differences in foraging behavior are clearly illustrated using these ordination techniques. Areas of strong overlap in foraging behavior across many parrotfish and surgeonfish species provide evidence for functional redundancy, while areas of non-overlap indicate complimentary grazing by the herbivore assemblage.

Substrate-specific grazing intensity, measured as bites $\mathrm{cm}^{-2} \mathrm{~d}^{-1}$ of available substrate in each reef habitat, was highest on mixed algal turfs in both the reef terrace and fore reef habitats (Table 2). On the reef terrace, we estimated that each $\mathrm{cm}^{2}$ of turf algae receives 5.8 bites $\mathrm{d}^{-1}$ from all herbivores combined, while this value is reduced to 3.1 bites $\mathrm{cm}^{-2} \mathrm{~d}^{-1}$, if Ctenochaetus spp. are removed from the calculations. Parrotfish $(>5 \mathrm{~cm}$ TL) that scrape or excavate substrates took 1.4 bites $\mathrm{cm}^{-2} \mathrm{~d}^{-1}$ on turf algae on the reef terrace. Grazing intensities were also high relative to the areal coverage of available substrate for the other macroalgal categories, but were low for CCA and corals (Table 2). Grazing intensities were distinctly lower on the fore reef than the reef terrace, but each $\mathrm{cm}^{2}$ of turf algae received 1.3 bites $\mathrm{d}^{-1}$ from all herbivorous fish; From scraping or excavating parrotfish, a bite was taken on each $\mathrm{cm}^{2}$ of available turf algae every 4 to $5 \mathrm{~d}$ on the fore reef (Table 2). These results, paired with a selectivity analysis conducted on the grazing intensity data (Fig. 6, Table S1), indicate that herbivorous fishes strongly preferred mixed algal turf in both habitats, consumed Halimeda in proportion to its abundance, avoided foliose macroalgae and significantly avoided CCA and corals. Guild-level selectivity profiles, using a bootstrapping procedure, indicated that the 
Table 1. Chlorurus spp., Scarus spp., Acanthurus spp., Ctenochaetus spp. Bite rates and defecation rates for focal parrotfish and surgeonfish species recorded on Palmyra Atoll and other published studies. GBR: Great Barrier Reef

\begin{tabular}{|c|c|c|c|c|}
\hline Species & Location & $\begin{array}{l}\text { Bite rate } \\
\left(\mathrm{min}^{-1}\right)\end{array}$ & $\begin{array}{l}\text { Defecation } \\
\text { rate }\left(\mathrm{min}^{-1}\right)\end{array}$ & Reference \\
\hline \multicolumn{5}{|l|}{ Parrotfish } \\
\hline \multirow[t]{5}{*}{ Chlorurus sordidus } & Palmyra Atoll & $12.3-15.6$ & $0.56-0.60$ & This study \\
\hline & Heron and Lizard Island, GBR & $13.8-14.9$ & 0.34 & $\begin{array}{l}\text { Bellwood \& Choat (1990), Choat } \\
\quad \& \text { Clements (1993) }\end{array}$ \\
\hline & Lizard Island, GBR & $16.6-19.8$ & & Bellwood (1995) \\
\hline & Moorea, French Polynesia & 17.6 & 0.22 & Polunin et al. (1995) \\
\hline & Egypt, Red Sea & 15.3 & & Alwany et al. (2009) \\
\hline \multirow[t]{2}{*}{ Chlorurus microrhinos } & Palmyra Atoll & 8.1 & 0.52 & This study \\
\hline & Orpheus Island, GBR & $\sim 8.0$ & & Fox \& Bellwood (2007) \\
\hline \multirow[t]{3}{*}{ Scarus frenatus } & Palmyra Atoll & $12.3-15.6$ & $0.11-0.28$ & This study \\
\hline & Heron Island, GBR & 12.2 & & Bellwood \& Choat (1990) \\
\hline & Egypt, Red Sea & 10.7 & & Alwany et al. (2009) \\
\hline \multirow[t]{2}{*}{ Scarus globiceps } & Palmyra Atoll & 34.4 & 0.70 & This study \\
\hline & Heron Island, GBR & 39.3 & & Bellwood \& Choat (1990) \\
\hline \multirow[t]{2}{*}{ Scarus oviceps } & Palmyra Atoll & $20.0-26.4$ & $0.15-0.31$ & This study \\
\hline & Heron Island, GBR & 12.9 & & Bellwood \& Choat (1990) \\
\hline \multirow{2}{*}{ Scarus psittacus } & Palmyra Atoll & 16.5 & 1.57 & This study \\
\hline & Heron and Lizard Island, GBR & $21.6-23.5$ & & Bellwood \& Choat (1990) \\
\hline \multirow[t]{3}{*}{ Scarus rubroviolaceus } & Palmyra Atoll & $8.0-11.4$ & $0.31-0.40$ & This study \\
\hline & Lizard Island, GBR & 10.1 & & Bellwood \& Choat (1990) \\
\hline & Oahu, Hawaii & $11.1-15.5$ & & Ong \& Holland (2010) \\
\hline \multirow[t]{2}{*}{ Scarus schlegeli } & Palmyra Atoll & 7.4 & 1.45 & This study \\
\hline & Lizard Island, GBR & 20.1 & & Bellwood \& Choat (1990) \\
\hline \multirow[t]{2}{*}{ Scarus spinus } & Palmyra Atoll & 42.0 & 0.38 & This study \\
\hline & Heron Island, GBR & 45.0 & & Bellwood \& Choat (1990) \\
\hline \multicolumn{5}{|l|}{ Surgeonfish } \\
\hline \multirow[t]{2}{*}{ Acanthurus lineatus } & Palmyra Atoll & 10.4 & 0.03 & This study \\
\hline & Aldabra Atoll, Indian Ocean & $\sim 24.0$ & & Robertson et al. (1979) \\
\hline \multirow[t]{3}{*}{ Ctenochaetus striatus } & Palmyra Atoll & 17.9 & 0.04 & This study \\
\hline & Moorea, French Polynesia & 17.5 & 0.12 & Alwany et al. (2009) \\
\hline & Lizard Island, GBR & $15.4-21.2$ & $0.07-0.19$ & Goatley \& Bellwood (2010) \\
\hline
\end{tabular}

Fig. 5. Principal components (PC) analysis of bite rate and bite composition data for surgeonfish (circles) and parrotfish (triangles) on the reef terrace (red) and fore reef (blue) of Palmyra Atoll. Mean $( \pm 1 \mathrm{SE})$ of PC1 and PC2 for each species illustrate within and among species variability in foraging behavior and differences among habitats. CCA: crustose coralline algae. See Fig. 4 for species names

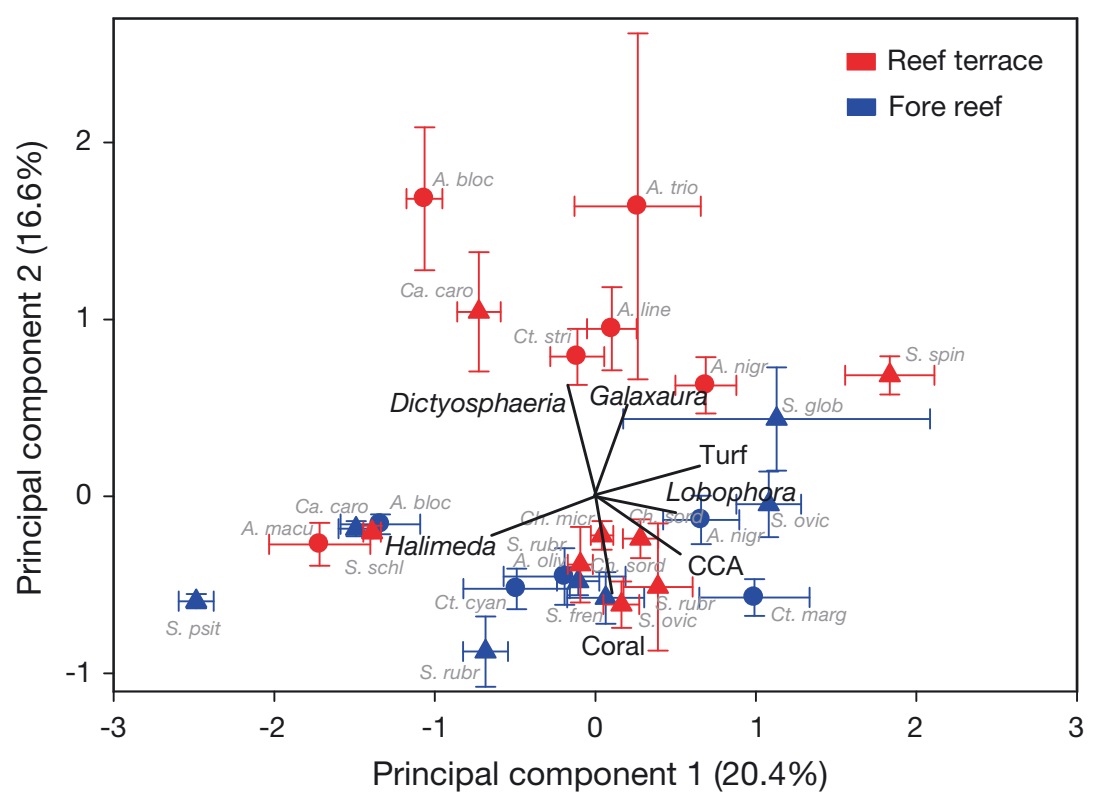


Table 2. Chlorurus spp., Acanthurus spp., Ctenochaetus spp., Scarus spp., Calotomus carolinus. Grazing intensity scaled to substrate availability for the roving herbivore fish community in 2 different reef habitats on Palmyra Atoll: reef terrace and fore reef. Values: daily number of bites $\mathrm{cm}^{-2}$ of each substrate at each habitat for (A) all surgeonfish and parrotfish combined (herbivores), (B) all species excluding Ctenochaetus spp. (which are primarily detritivores), and separately for (C) surgeonfish (including Ctenochaetus spp.) and (D) parrotfish. Grazing intensities were calculated based on the species-specific average bites rates on each substrate (bites $\mathrm{min}^{-1}$ ), the average density of each herbivore species (fish $\mathrm{m}^{-2}$ ), and the percent cover of each substrate type on the reef terrace and fore reef. (E) Grazing intensity ratios: difference in grazing rates on each substrate between the reef terrace and fore reef, where values $>1$ imply greater grazing pressure on the reef terrace.

CCA: crustose coralline algae

\begin{tabular}{|c|c|c|c|c|c|}
\hline & Turf algae & $\mathrm{CCA}$ & Coral & Halimeda & Foliose macroalgae \\
\hline \multicolumn{6}{|l|}{ (A) Herbivores (bites $\mathrm{cm}^{-2} \mathrm{~d}^{-1}$ ) } \\
\hline Reef terrace & 5.9 & 0.2 & 0.02 & 1.2 & 0.8 \\
\hline Fore reef & 1.3 & 0.1 & 0.02 & 0.3 & 0.1 \\
\hline \multicolumn{6}{|c|}{ (B) Herbivores excluding Ctenochaetus spp. (bites $\mathrm{cm}^{-2} \mathrm{~d}^{-1}$ ) } \\
\hline Reef terrace & 3.1 & 0.1 & 0.02 & 0.4 & 0.3 \\
\hline Fore reef & 0.8 & 0.05 & 0.02 & 0.2 & 0.04 \\
\hline \multicolumn{6}{|l|}{ (C) Surgeonfish (bites $\mathrm{cm}^{-2} \mathrm{~d}^{-1}$ ) } \\
\hline Reef terrace & 4.4 & 0.08 & 0.01 & 0.9 & 0.5 \\
\hline Fore reef & 1.1 & 0.08 & 0.01 & 0.3 & 0.09 \\
\hline \multicolumn{6}{|l|}{ (D) Parrotfish (bites $\mathrm{cm}^{-2} \mathrm{~d}^{-1}$ ) } \\
\hline Reef terrace & 1.4 & 0.1 & 0.02 & 0.3 & 0.1 \\
\hline Fore reef & 0.2 & 0.02 & 0.01 & 0.08 & 0.01 \\
\hline \multicolumn{6}{|c|}{ (E) Grazing intensity ratio (reef terrace:fore reef) } \\
\hline All herbivores & 4.4 & 1.9 & 1.2 & 3.5 & 5.9 \\
\hline Excluding Ctenochaetus spp. & 3.7 & 2.5 & 1.2 & 2.4 & 7.0 \\
\hline
\end{tabular}

substrate-specific distribution of total bites (i.e. the 'rain of bites') was significantly different than the expected null distribution on the fore reef and reef terrace ( $p<0.001$ for both habitats), but did not differ among reef habitats. Our calculations suggest that there is strong top-down control on turf algae by roving herbivorous fishes on Palmyra's reefs. Interest-

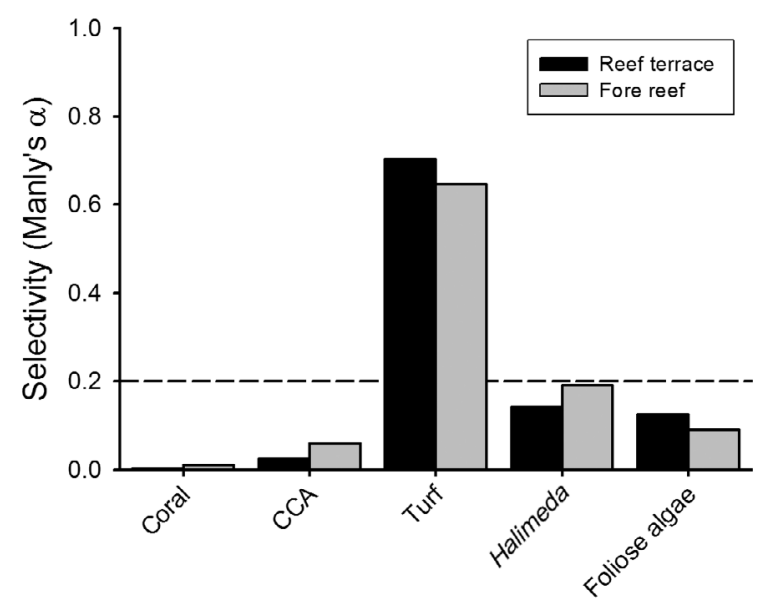

Fig. 6. Manly's $\alpha$ selectivity index for all herbivorous fish biting on 5 different substrate types on the reef terrace and fore reef. Dashed line at $\alpha=0.2$ : null expectation of equal selectivity for each substrate based on its availability in the environment ingly, species-specific differences in selectivity indicate that while many parrotfish forage on turf algae more than expected in relation to its abundance on the benthos, many surgeonfish show stronger selection for foliose macroalgae, particularly in the fore reef habitat (Table S1).

For all co-occurring herbivorous fish species on the reef terrace and fore reef, mean total bite rates were consistently greater in the fore reef habitat than the reef terrace habitat (paired $t$-test, $t_{7}=6.58, \mathrm{p}=$ 0.0003 ; Fig. 7). The percent change in total bite rates between reef habitats varied among species with increases from 13 to $138 \%$ (mean $=45 \%$ increase) on the fore reef. Despite the fact that individuals consistently exhibited higher bites rates on the fore reef, compensatory changes in substrate-specific grazing intensities were not observed. Substrate-specific grazing intensities were significantly greater at the reef terrace sites relative to the fore reef sites (Table 2E) because preferred foraging substrate availability was significantly lower (the reef terrace was dominated by live coral), the densities and biomass of herbivores were significantly higher on the reef terrace, and substrate selectivity was similar between the 2 habitats. Grazing intensity ratios among habitats were similar if Ctenochaetus spp. were included or excluded from the analysis. 


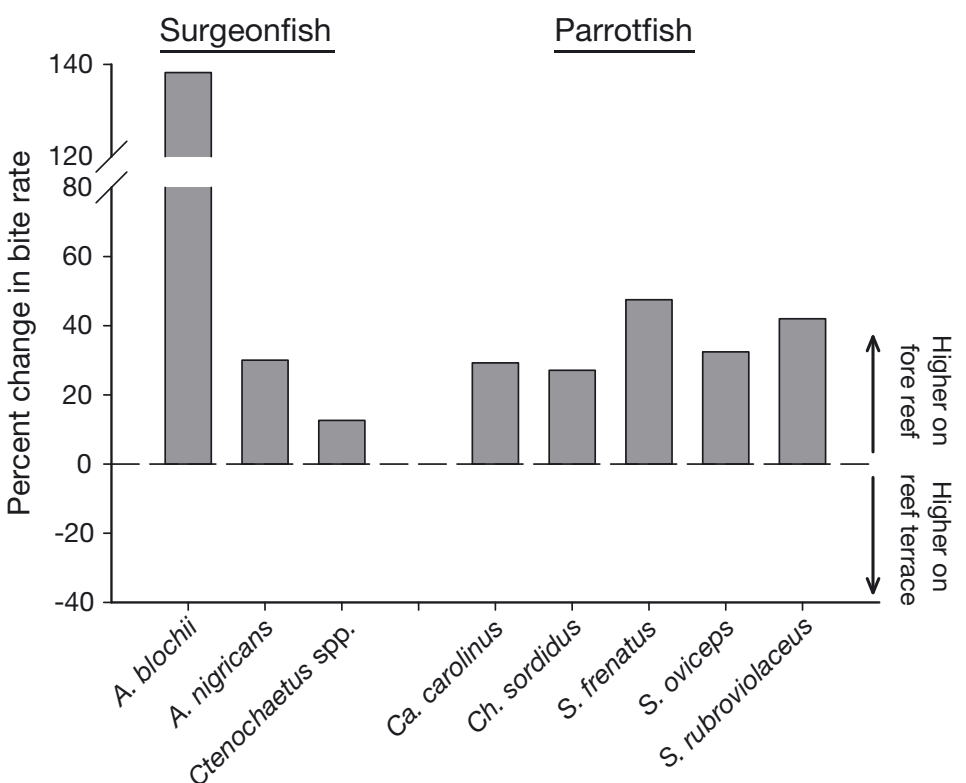

bite rates on Palmyra were somewhat lower than the values reported in other studies, which may be a response to differences in predation risk, resource availability, or algal nutritional quality among locations. Species of parrotfish and surgeonfish differed in their bite rates, but they also differed in the types of substrates that they grazed on. Most species grazed preferably on mixed algal turf assemblages (Figs. 4 \& 6), while some species were more generalists (Acanthurus blochii on the terrace and Ctenochaetus cyanochelius and $S$. rubroviolaceus in both habitats), and others consumed Halimeda almost exclusively (A. blochii, Calotomus carolinus, and $S$. psittacus on the fore reef, and A. maculiceps and S. schlegelii on the reef terrace). As a group, both the parrot-

Fig. 7. Acanthurus spp., Ctenochaetus spp., Chlorurus spp., Scarus spp., Calotomus carolinus. Comparison (in \%) of the percent change in mean total bite rates (bites $\mathrm{min}^{-1}$ ) between reef habitats of herbivorous fish species that co-occur at fore reef and reef terrace sites on Palmyra Atoll. For every species studied, total bite rates were higher at fore reef locations

We found a significant positive relationship between the percent of bites taken on Halimeda (a calcareous green alga) and defecation rate (Fig. 8). This relationship was consistent for parrotfish $\left(F_{1,7}=24.9\right.$, $\left.\mathrm{r}^{2}=0.78, \mathrm{p}=0.0016\right)$ and surgeonfish $\left(F_{1,7}=25.0, \mathrm{r}^{2}=\right.$ $0.80, \mathrm{p}=0.0024)$, suggesting rapid processing and gut passage times for fish that focus their foraging efforts on highly calcified seaweeds.

\section{DISCUSSION}

Palmyra Atoll is a predator-dominated system with high total fish biomass $\left(2.6 \mathrm{t} \mathrm{ha}^{-1}\right)$, mainly in the apex predator class ( $65 \%$ of the fish biomass on Palmyra is composed of piscivores; Sandin et al. 2008). Despite high predator biomass, bite rates of parrotfish on Palmyra, measured as total bites $\min ^{-1}$ on all substrates, were surprisingly similar to the values for the same species reported in previous studies throughout the Indo-Pacific (Table 1), highlighting constraints of phylogeny and diet on foraging behavior. The highest grazing rates were recorded across multiple studies for Scarus spinus and $S$. globiceps, intermediate rates for Chlorurus sordidus, $S$. frenatus, and $S$. oviceps, and lowest rates for larger body size species $C$. microrhinos and $S$. rubroviolaceus. For most species,

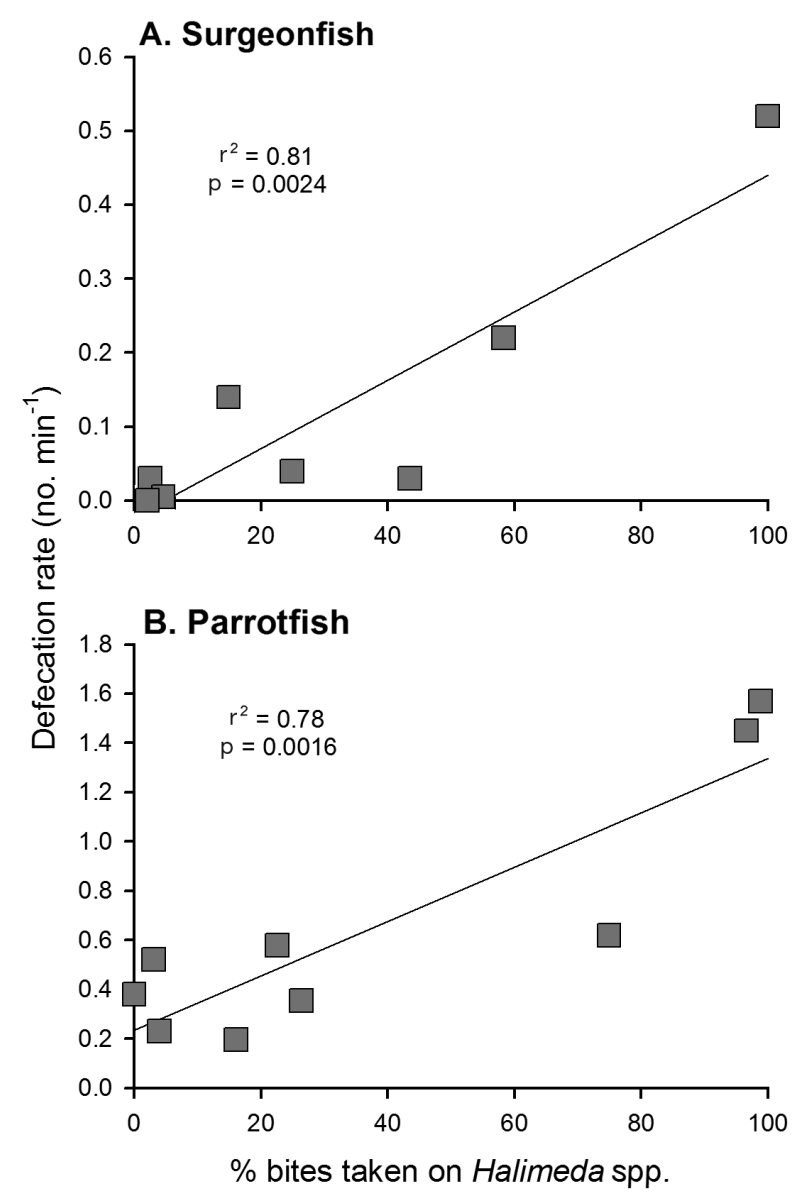

Fig. 8. Acanthurus spp., Ctenochaetus spp., Chlorurus spp., Scarus spp., Calotomus calorinus. Relationship between the proportion of bites taken on Halimeda spp. and defecation rate for (A) surgeonfish and (B) parrotfish species averaged across reef habitats on Palmyra Atoll 
fishes and surgeonfishes overwhelmingly prefer mixed algal turfs, even if particular species are specialists; this pattern of group-level selectivity is upheld across habitats, irrespective of resource availability or predation risk (Fig. 6).

The elevated foraging rates we measured on the fore reef are counter to the predictions of reduced foraging in response to higher levels of predation risk. For the roving herbivores Acanthurus nigricans and Chlorurus sordidus that we also studied, Madin et al. (2010) reported negative relationships between excursion area and 2 measures of the threat of predation (total predator biomass and acute predation risk) across 3 islands (including Palmyra). In contrast, we found consistently higher foraging rates (bites $\mathrm{min}^{-1}$ ) for all herbivorous fish on the fore reef of Palmyra where predator density and biomass is 3.3 and 5.6 times higher, respectively (S. A. Sandin unpubl. data), than the shallow reef terrace. In fact, herbivore density and biomass are elevated on the reef terrace while preferred food resources such as mixed algal turf abundance is lower. Therefore, resource competition may limit foraging rates on the reef terrace compared to the fore reef, despite reductions in predation risk in that habitat. Environmental differences between habitat types on Palmyra could also explain differences in foraging rates. Relative to the reef terrace, the deeper fore reef sites receive lower levels of irradiance (i.e. lower productivity rates), and these exposed sites also experience much higher water motion and surge due to wave action, which may inhibit foraging. If anything, these environmental factors would act to suppress grazing rates on the fore reef, counter to our observations. However, it is also possible that the algal communities on the shallow reef terrace are more productive and have a higher turnover rate per unit area, despite low standing stock, due to higher levels of irradiance and high grazing pressure.

Diet composition affected the frequency of defecation, and thus detritus production, on Palmyra's reefs. Defecation rates presumably scale with grazing rates, but may be dependent upon palatability/ digestibility of algal resources (Goatley \& Bellwood 2010), and can be significant sources of organic (Max et al. 2013) and inorganic nutrients (de Loma \& Harmelin-Vivien 2002) and carbonate (Perry et al. 2011) to the benthos. Fig. 8 suggests that defecation is linked positively to the consumption of the erect, calcareous green algae in the genus Halimeda, with the positive relationship driven largely by the extremely high rates of defecation in species that forage almost exclusively on Halimeda, so-called 'obli- gate Halimeda-vores'. Given the highly calcified tissues of Halimeda, much of the ingested material is indigestible carbonate minerals. Thus, rapid gut passage times are likely necessary to meet nutritional requirements. Therefore, the grazing activities of species like Scarus psittacus and Acanthurus maculiceps are likely to contribute disproportionately to sand/carbonate production on a per individual basis. Polunin et al. (1995) compared algal food processing of 5 herbivorous fishes and found that gut passage and defecation rates were highest for Chlorurus sordidus (a species with high levels of carbonates in their gut) in contrast to damselfish and surgeonfish that consumed mainly fleshy macroalgae, again highlighting the importance of these taxa for the carbonate budgets on reefs.

From the perspective of the benthos, grazing intensities (or the 'rain of bites' across the landscape) are extremely high on Palmyra, despite high predator biomass. Every $\mathrm{cm}^{2}$ of available turf algae is manipulated by a fish mouth $\sim 6$ times $\mathrm{d}^{-1}$ on the shallow reef terrace and 1.3 times $\mathrm{d}^{-1}$ on the fore reef (Table 2). This is due to the high abundance of grazers on the shallow terrace and low percent cover of turf algae in this habitat (Figs. 1-3). Our absolute measures of grazing intensity may be a slight overestimate because bite rates of some herbivores change throughout the diel cycle, peaking in mid-day, and we were only able to observe foraging behaviors between 10:00 and 16:00 h. Bellwood (1995) showed that bite rates quickly approach the daily maximum within an hour either side of sunrise or sunset, so we calculated grazing intensity based on a $10 \mathrm{~h}$ instead of a $12 \mathrm{~h}$ day. For the species studied on Palmyra, we did not detect any significant relationship between time of day and bite rates during our observation window (S. A. Sandin unpubl. data).

Previous studies have indicated that Ctenochaetus spp. are detritivores that remove sediment and organic material from algal surfaces, causing little damage to algal turfs (Purcell \& Bellwood 1993). However, a recent experimental study showed significant removal of turf algae by the foraging activities of C. striatus (Marshell \& Mumby 2012). Thus, to be conservative, we presented data including and removing the influence of these species on grazing intensity calculations (Table 2). Fox \& Bellwood (2007) used information on fish density, bite rates, and mouth sizes to estimate grazing pressure on algal turfs, finding that the 2 most common species of parrotfish grazed up to $150 \%$ of the substratum per month on the reef crest, with lower grazing pressure in other reef habitats. Unfortunately, we do not pos- 
sess species-specific data on the relationship between fish size and bite size needed to conduct a similar analysis on Palmyra. Nonetheless, grazing pressures appear to be relatively intense in this system, likely due to the low availability of algal turfs and high abundance of parrotfish and surgeonfish; herbivorous fish biomass on Palmyra is similar to that of many other unfished locations in the central Pacific (Edwards et al. 2013).

An important point to note is that our estimates of substrate-specific bite rates ignore the 3-dimensional complexity of the reef's surface area. Instead, we are providing estimates that scale with the availability of substrates to direct incident light (i.e. area viewed when looking at the reef from straight above). We recognize that the reefscape is not 2-dimensional, and as such, our estimates should be viewed within the scope of this approximation. Importantly, there are minor differences in topographical complexity across the 2 habitats, making the relative comparison robust. However, in order to estimate the true bite rate per unit surface area of the reef, we will need to make use of new imaging tools or other approaches that allow the direct estimation of the surface area across the complex 3-dimensional surface of benthic reef habitats. Even accounting for these topographical constraints, the impact of the high bite rates to algal turf abundance, growth, and productivity will be tied to mouth morphology and bite size of the individual herbivores, which will vary within and among species.

Our foraging observations and the ordination analysis (Fig. 5) across the entire roving herbivore guild indicate that there is a high level of functional redundancy on Palmyra Atoll, in addition to complementarity of foraging behavior throughout the herbivore guild. There is high resource use overlap on Palmyra in that many species of parrotfish and surgeonfish graze on the same algal food resource (primarily turf algae) and have similar bite rates and purported impacts on the benthos. Even for those herbivorous fish that are specialists on one type of macroalgae, such as Halimeda, functional redundancy is present. However, although there are many species that appear to consume the same food resources, there are still large differences in how individual species interact with the benthos, where some are delicately grazing and others are actively scraping and excavating the reef substrate (Bellwood \& Choat 1990, Green \& Bellwood 2009). Nonetheless, the high diversity of herbivores and dietary overlap may help to explain high levels of resilience of intact reef systems like Palmyra. Burkepile \& Hay (2008) showed that grazing by one species of parrotfish and one species of surgeonfish in the Caribbean was complimentary and enhanced reef resilience because each type of herbivore consumed different types of algae, thereby reducing coral-algal competition; similar patterns are likely occurring in the Pacific where herbivore diversity is much higher (Bellwood et al. 2004, Roff \& Mumby 2012).

Other herbivores such as sea urchins are extremely rare on Palmyra's reefs (Sandin et al. 2008, McCauley et al. 2010), so fish are the major grazers whose foraging behavior helps to prevent algal overgrowth of hard corals. When fish grazing activities are excluded from carbonate surfaces or from artificial settlement tiles in Palmyra, turf algae grow rapidly (McCauley et al. 2010, J. E. Smith unpubl. data); Therefore, herbivorous fish play an essential role in maintaining a healthy coral-dominated ecosystem state. In the Caribbean, theoretical work has suggested that herbivorous fish are only capable of supplying enough grazing pressure in the absence of sea urchins to maintain a coral-dominated state if initial coral cover is relatively high (Mumby et al. 2007, Roff \& Mumby 2012). Coral cover is consistently higher and macroalgal cover is consistently lower in the Indo-Pacific than the Caribbean (Roff \& Mumby 2012), which may allow fish to play a larger role in maintaining reef resilience in the former. Further, because herbivorous fish biomass is more than 2-fold lower on reefs accessible to fishing than in those where fishing is banned (Edwards et al. 2013), it is likely that humans are directly affecting the potential for grazers to maintain reef health. It remains to be seen on Palmyra whether fish grazing is sufficient to maintain reef resilience in the face of future global change; however, studies to date suggest relatively rapid recovery of Palmyra's reef to disturbances, such as warming induced bleaching events (Williams et al. 2010).

In conclusion, we have quantified the foraging behaviors and calculated grazing intensities for the roving herbivore guild across 2 reef habitats in a remote and healthy coral reef system. We found striking differences in substrate-specific grazing intensities by herbivore species, differences in abundance and bite rates across habitats, and higher individual-specific bite rates in the exposed predatordominated fore reef habitat. This study highlights the value of functional redundancy in herbivore assemblages for controlling algal growth and the importance of quantifying the varied impacts of different herbivore species on the suite of algal resources available. 
Acknowledgements. For logistical support we thank the Nature Conservancy, the US Fish and Wildlife Service, the National Fish and Wildlife Refuge System, and PARC (Palmyra Atoll Research Consortium). We also thank K. Pollock, A. Meyer, S. Smirga, M. Garren, J. Baum, and T. Davies for assistance in the field; and B. Zgliczynski for creating the map in Fig. 1. Helpful comments were provided by 3 anonymous reviewers. Funding was generously provided by donations from Scott Wilson and the MarIsla Foundation. This is Palmyra Atoll Research Consortium contribution number PARC-101.

\section{LITERATURE CITED}

Alwany MA, Thaler E, Stachowitsch M (2009) Parrotfish bioeroision on Egyptian Red Sea reefs. J Exp Mar Biol Ecol 371:170-176

Barott KL, Williams GJ, Vermeij MJA, Harris J, Smith JE, Rohwer FL, Sandin SA (2012) Natural history of coralalgae competition across a gradient of human activity in the Line Islands. Mar Ecol Prog Ser 460:1-12

> Bellwood DR (1995) Direct estimate of bioerosion by two parrotfish species, Chlorurus gibbus and C. sordidus, on the Great Barrier Reef, Australia. Mar Biol 121:419-429

Bellwood DR, Choat JH (1990) A functional analysis of grazing in parrotfishes (family: Scaridae): the ecological implications. Environ Biol Fishes 28:189-214

Bellwood DR, Hughes TP, Folke C, Nystrom M (2004) Confronting the coral reef crisis. Nature 429:827-833

Bellwood DR, Hughes TP, Hoey AS (2006) Sleeping functional group drives coral-reef recovery. Curr Biol 16: 2434-2439

Burkepile DE, Hay ME (2008) Herbivore species richness and feeding complementarity affect community structure and function on a coral reef. Proc Natl Acad Sci USA 105: 16201-16206

Burkepile DE, Hay ME (2010) Impact of herbivore identity on algal succession and coral growth on a Caribbean reef. PLoS ONE 5:e8963

Carpenter RC (1986) Partitioning herbivory and its effects on coral reef algal communities. Ecol Monogr 56:345-363

> Cheal AJ, MacNeil MA, Cripps E, Emslie MJ, Jonker M, Schaffelke B, Sweatman H (2010) Coral-macroalgal phase shifts or reef resilience: links with diversity and functional roles of herbivorous fishes on the Great Barrier Reef. Coral Reefs 29:1005-1015

> Chesson J (1983) The estimation and analysis of preference and its relationship to foraging models. Ecology 64: 1297-1304

Choat JH (1991) The biology of herbivorous fishes on coral reefs. In: Sale PF (ed) The ecology of fishes on coral reefs. Academic Press, San Diego, CA, p 120-155

> Choat JH, Clements KD (1993) Daily feeding rates in herbivorous labroid fishes. Mar Biol 117:205-211

> de Loma TL, Harmelin-Vivien ML (2002) Summer fluxes of organic carbon and nitrogen through a damselfish resident, Stegastes nigricans (Lacepede, 1803), on a coral reef flat at La Reunion (Indian Ocean). Mar Freshw Res 53:169-174

Edwards CB, Friedlander AM, Green AG, Hardt MJ and others (2013) Global assessment of the status of coral reef herbivorous fishes: evidence of fishing effects. Proc R Soc Lond B Biol Sci 281:20131835

Elmqvist T, Folke C, Nyström M, Peterson G, Bengtsson J,
Walker B, Norberg J (2003) Response diversity, ecosystem change, and resilience. Front Ecol Environ 1: 488-494

Estes JA, Terborgh J, Brashares JS, Power ME and others (2011) Trophic downgrading of planet earth. Science 333:301-306

Fox RJ, Bellwood DR (2007) Quantifying herbivory across a coral reef depth gradient. Mar Ecol Prog Ser 339: 49-59

Froese R, Pauly D (2007) FishBase, available at www. fishbase.org

> Goatley CHR, Bellwood DR (2010) Biologically mediated sediment fluxes on coral reefs: sediment removal and offreef transportation by the surgeonfish Ctenochaetus striatus. Mar Ecol Prog Ser 415:237-245

Green AL, Bellwood DR (2009) Monitoring functional groups of herbivorous reef fishes as indicators of coral reef resilience. A practical guide for coral reef managers in the Asia Pacific Region. International Union for Conservation of Nature (IUCN) working group on Climate Change and Coral Reefs. IUCN, Gland

> Hughes TP, Bellwood DR, Folke CS, McCook LJ, Pandolfi JM (2007) No-take areas, herbivory and coral reef resilience. Trends Ecol Evol 22:1-3

Kulbicki M, Guillemot N, Amand M (2005) A general approach to length-weight relationships for New Caledonian lagoon fishes. Cybium 29:235-252

Lewis SM (1986) The role of herbivorous fishes in the organization of a Caribbean reef community. Ecol Monogr 56: $184-200$

Madin EMP, Gaines SD, Warner RR (2010) Field evidence for pervasive indirect effects of fishing on prey foraging behavior. Ecology 91:3563-3571

Marshell A, Mumby PJ (2012) Revisiting the functional roles of the surgeonfish Acanthurus nigrofuscus and Ctenochaetus striatus. Coral Reefs 31:1093-1101

> Max LM, Hamilton SL, Gaines SD, Warner RR (2013) Benthic processes and overlying fish assemblages drive the composition of benthic detritus on a central Pacific coral reef. Mar Ecol Prog Ser 482:181-195

McCauley DJ, Micheli F, Young HS, Tittensor DP and others (2010) Acute effects of removing large fish from a nearpristine coral reef. Mar Biol 157:2739-2750

Mumby PJ, Harborne AR (2010) Marine reserves enhance the recovery of corals on Caribbean reefs. PLoS ONE 5: e8657

> Mumby PJ, Steneck RS (2008) Coral reef management and conservation in light of rapidly evolving ecological paradigms. Trends Ecol Evol 23:555-563

> Mumby PJ, Dahlgren CP, Harborne AR, Kappel CV and others (2006) Fishing, trophic cascades, and the process of grazing on coral reefs. Science 311:98-101

> Mumby PJ, Hastings A, Edwards HJ (2007) Thresholds and the resilience of Caribbean coral reefs. Nature 450: 98-101

> Nystrom M (2006) Redundancy and response diversity of functional groups: implications for the resilience of coral reefs. Ambio 35:30-35

Ong L, Holland KN (2010) Bioerosion of coral reefs by two Hawaiian parrotfishes: species, size differences and fishery implications. Mar Biol 157:1313-1323

Perry CT, Salter MA, Harborne AR, Crowley SF, Jelks HL, Wilson RW (2011) Fish as major carbonate mud producers and missing components of the tropical carbonate factory. Proc Natl Acad Sci USA 108:3865-3869 
Polunin NVC, Harmelin-Vivien MH, Galzin R (1995) Contrasts in algal food processing among five herbivorous coral-reef fishes. J Fish Biol 47:455-465

Preskitt L, Vroom P, Smith C (2004) A rapid ecological assessment (REA) quantitative survey method for benthic algae using photo quadrats with SCUBA. Pac Sci 58: 201-209

Purcell SW, Bellwood DR (1993) A functional analysis of food procurement in two surgeonfish species, Acanthurus nigrofuscus and Ctenochaetus striatus (Acanthuridae). Environ Biol Fishes 37:139-159

R Development Core Team (2010) R: a language and environment for statistical computing. R Foundation for Statistical Computing, Vienna; available at www.rproject.org

Robertson DR, Polunin NVC, Leighton K (1979) The behavioral ecology of three Indian Ocean surgeonfishes (Acanthurus lineatus, A. leucosternon, and Zebrasoma scopas): their feeding strategies, and social mating systems. Environ Biol Fishes 4:125-170

Roff G, Mumby PJ (2012) Global disparity in the resilience of

Editorial responsibility: Kenneth Heck,

Dauphin Island, Alabama, USA coral reefs. Trends Ecol Evol 27:404-413

Sandin SA, Smith JE, DeMartini EE, Dinsdale EA (2008) Baselines and degredation of coral reefs in the Northern Line Islands. PLoS ONE 3(2):e1548

Strong DR (1992) Are trophic cascades all wet? Differentiation and donor-control in speciose ecosystems. Ecology 73:747-754

Terborgh J, Estes JA (2010) Trophic cascades: predators, prey, and the changing dynamics of nature. Island Press, Washington, DC

van Rooij JM, Videler JJ, Bruggemann JH (1998) High biomass and production but low energy transfer efficiency of Caribbean parrotfish: implications for trophic models of coral reefs. J Fish Biol 53:A154-A178

> Williams GJ, Knapp IS, Maragos JE, Davy SK (2010) Modeling patterns of coral bleaching at a remote Central Pacific atoll. Mar Pollut Bull 60:1467-1476

- Williams GJ, Smith JE, Conklin EJ, Gove JM, Sala E, Sandin SA (2013) Benthic communities at two remote Pacific coral reefs: effects of reef habitat, depth, and wave energy gradients on spatial patterns. PeerJ 1:e81

Submitted: June 28, 2013; Accepted: December 4, 2013 Proofs received from author(s): February 19, 2014 